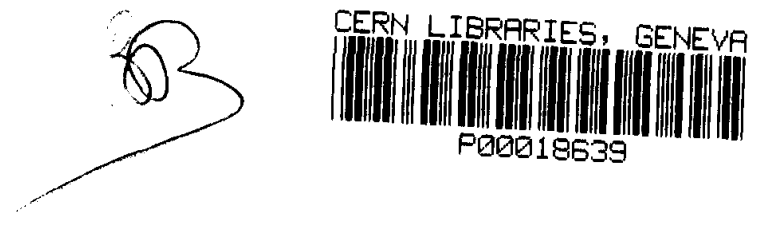

INSTITUTE OF THEORETICAL PHYSICS

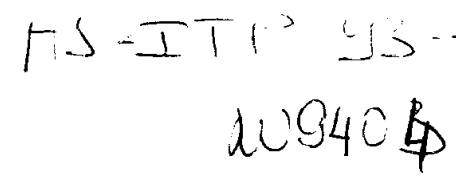

ASITP

ACADEMIA SINICA

AS-ITP-93-74

December 1993

\title{
AN IBM2 DESCRIPTION ON THE \\ STAGGERING PHENOMENON IN THE \\ BARIUM ISOTOPES
}

\author{
Yu-xin LIU Da-li ZHANG \\ Qi-zhi HAN En-guang ZHAO
}

P.O.Box 2735, Beijing 100080, The People's Republic of China

Telefax : (86)-1-2562587

Telex : 22040 BAOAS CN
Telephone : 2568348

Cable : 6158 
WIIII

III

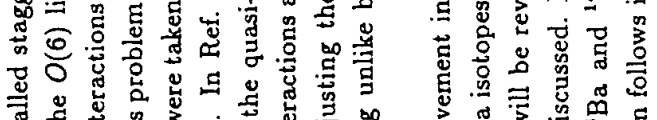

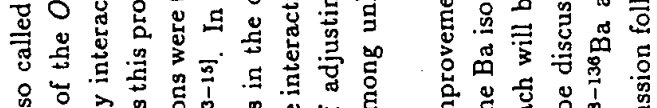

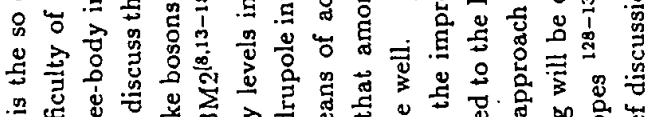

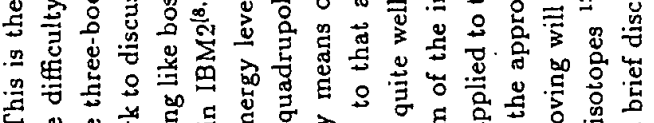

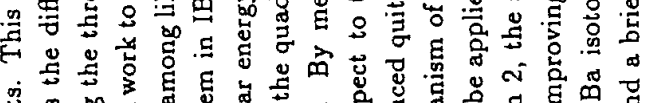

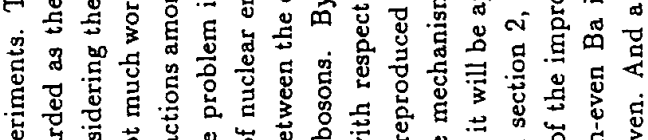

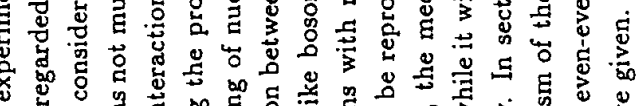

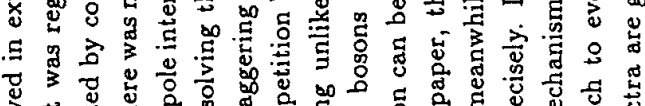

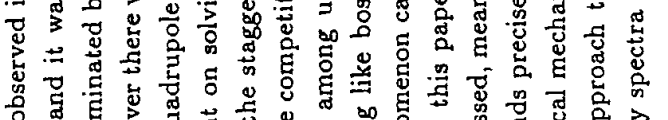

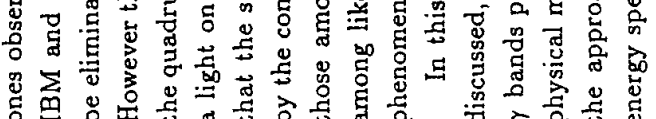

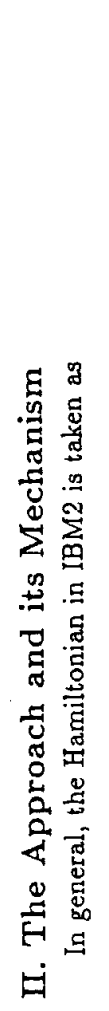

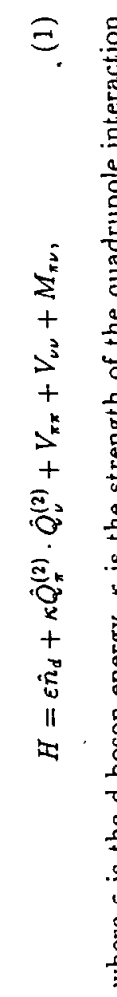

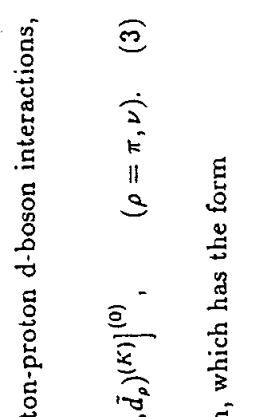

ए

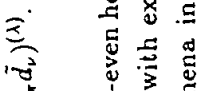

'ปै

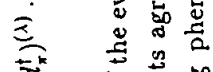

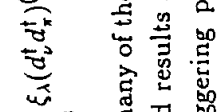

W है है

要

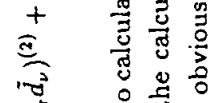
造

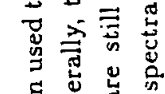

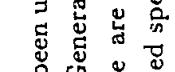

产

क्षे

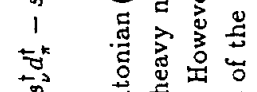

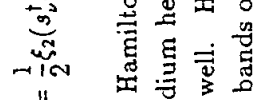

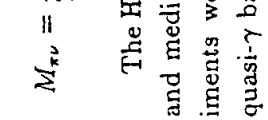

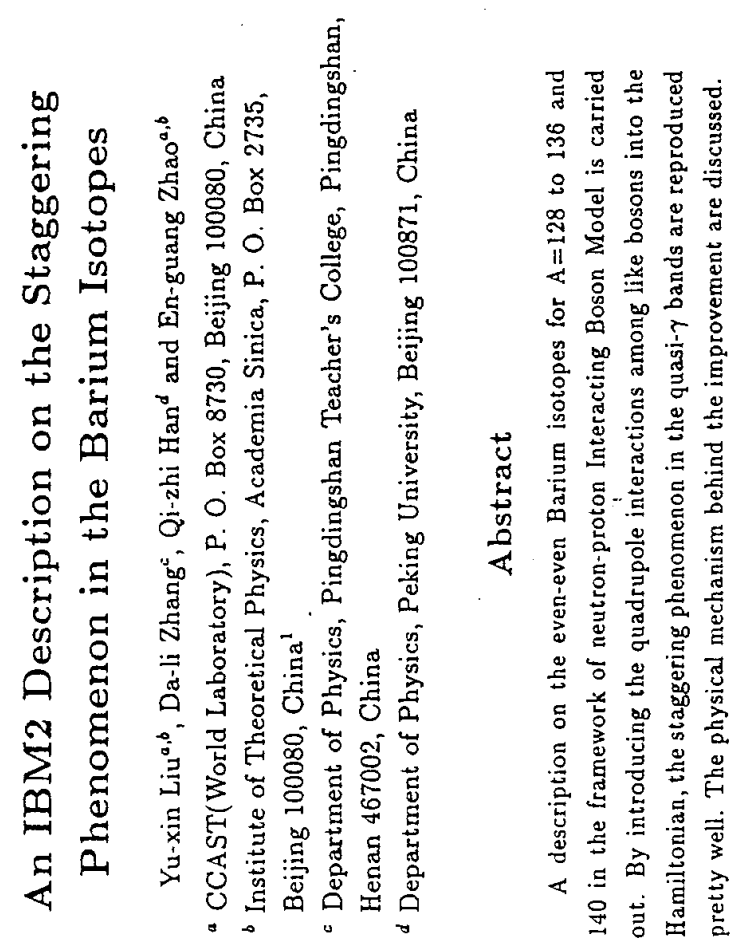

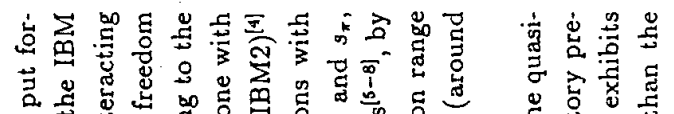

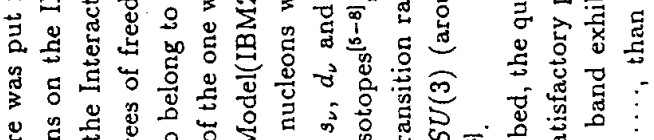

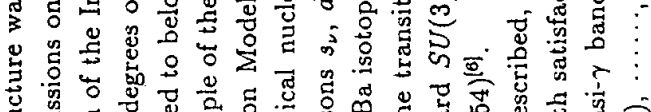

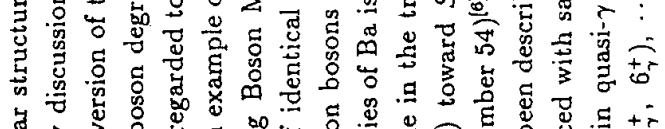

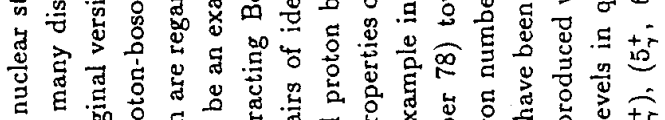

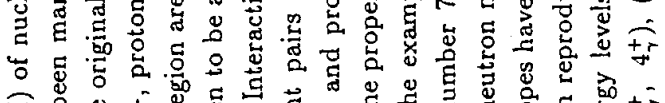

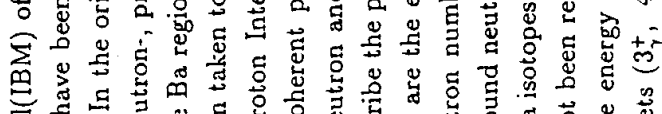

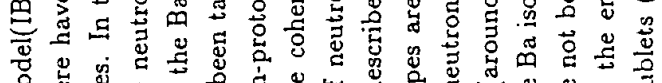

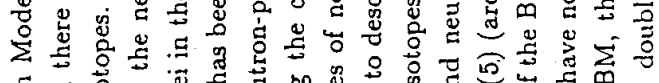

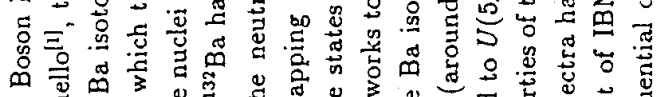

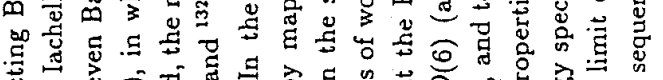

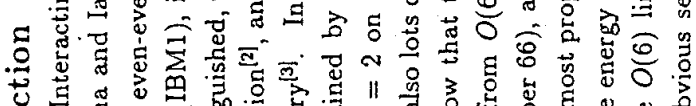

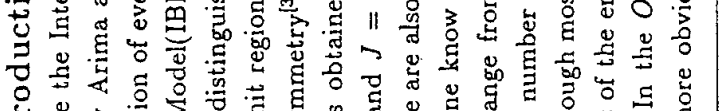

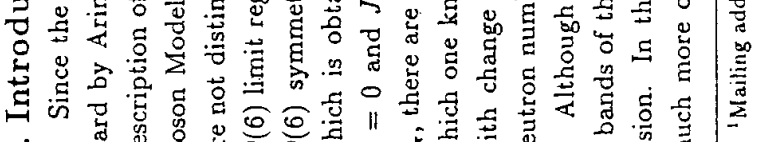




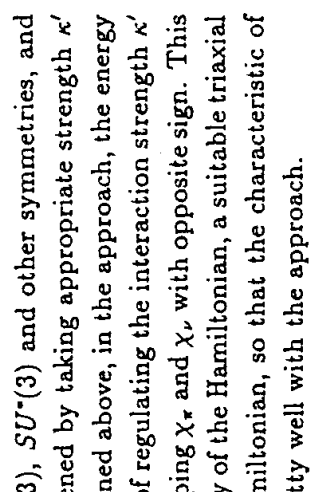

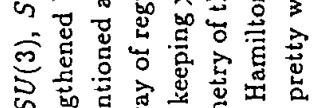

के

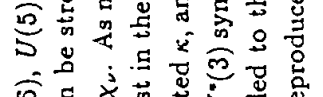

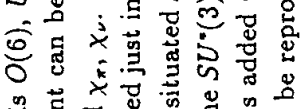

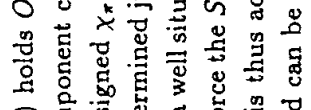

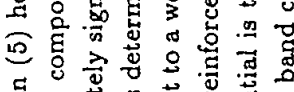

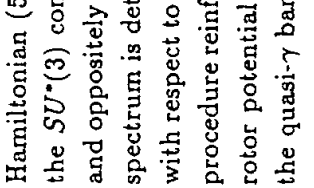

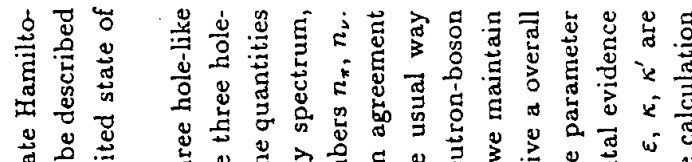

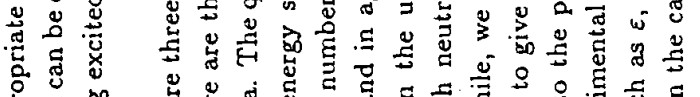

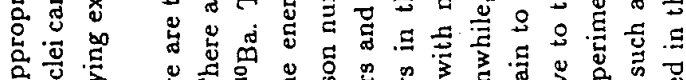

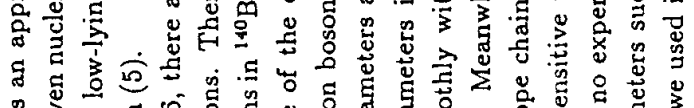
.

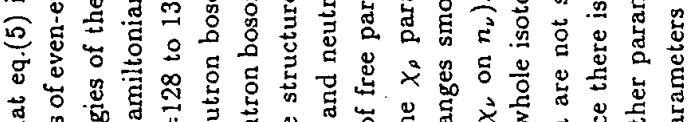

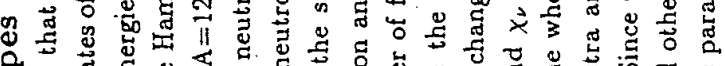

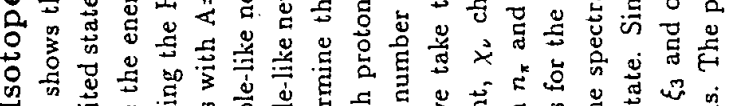

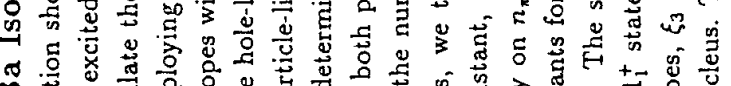

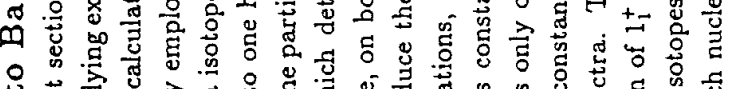

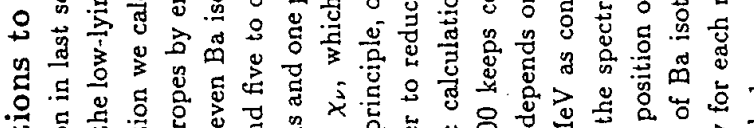

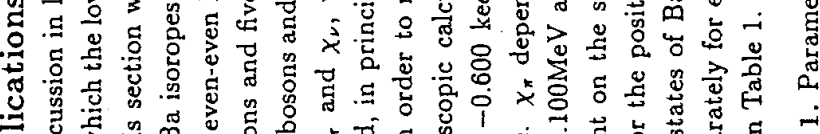

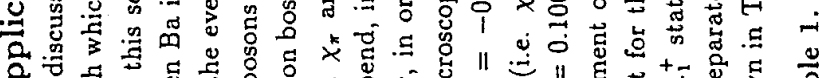

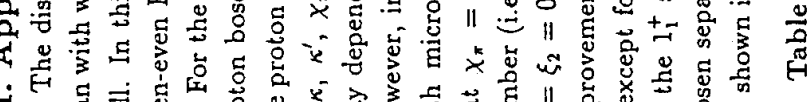

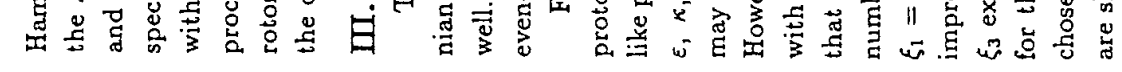

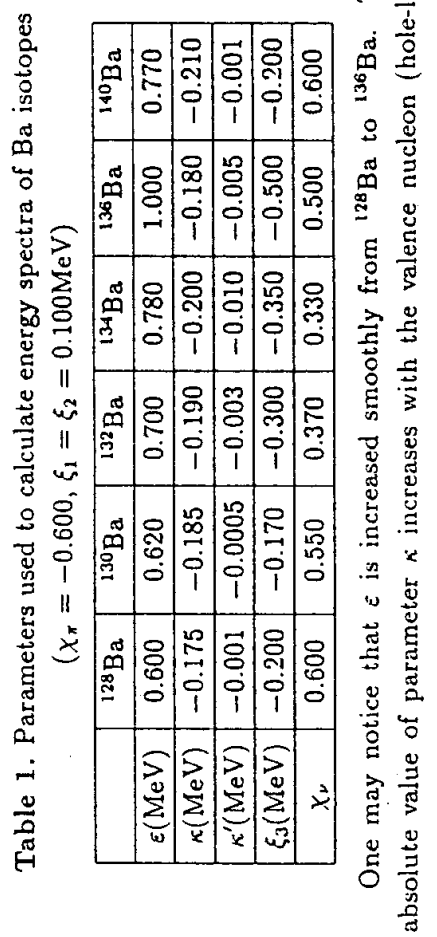

壱

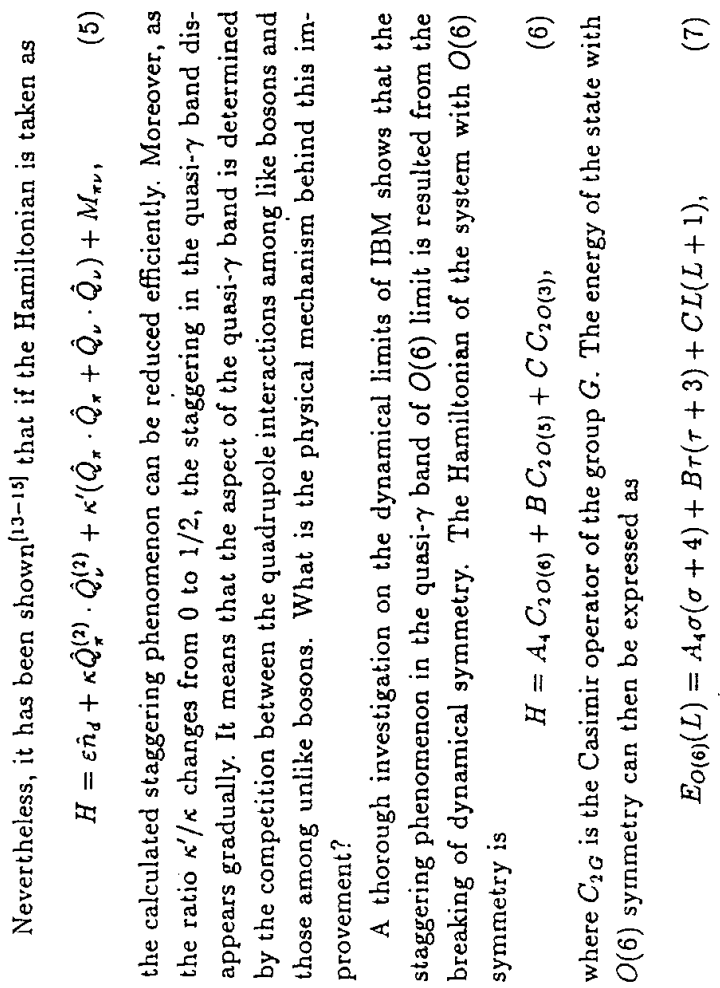

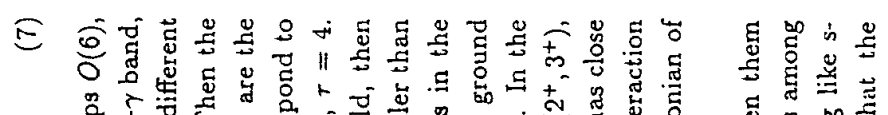

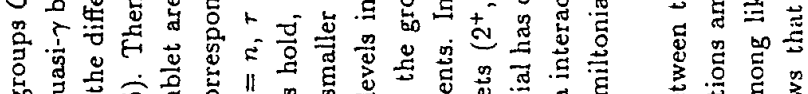

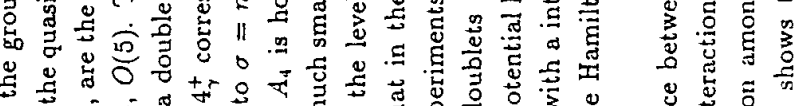

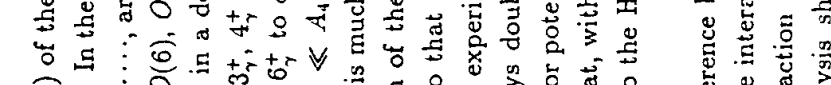

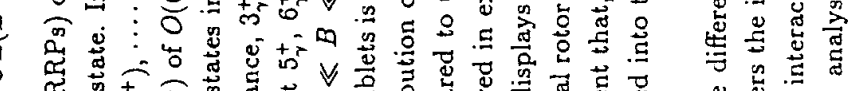

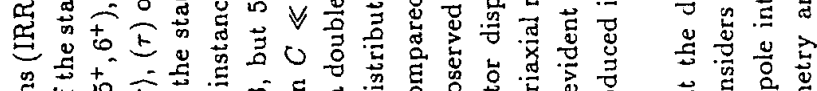

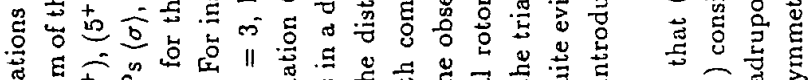

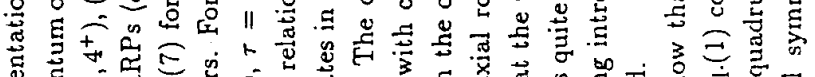

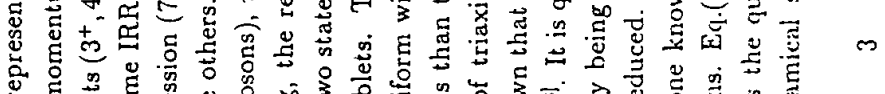

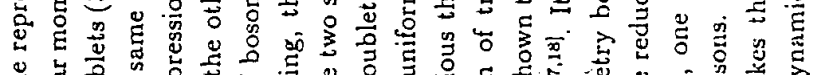

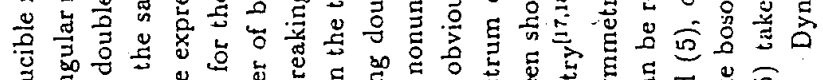

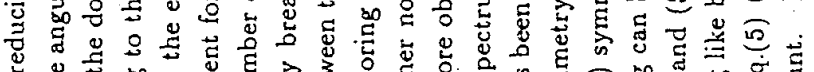

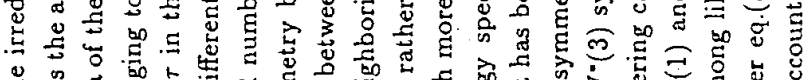

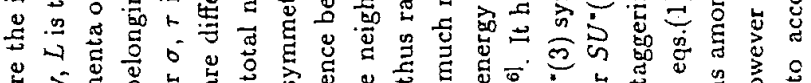

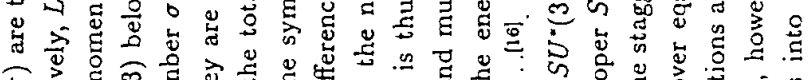

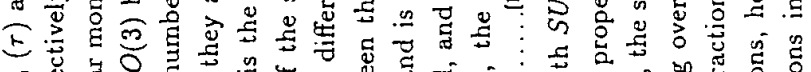

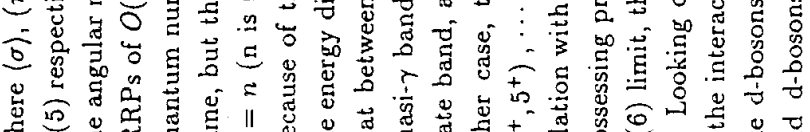

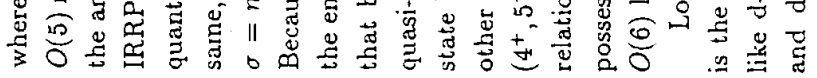



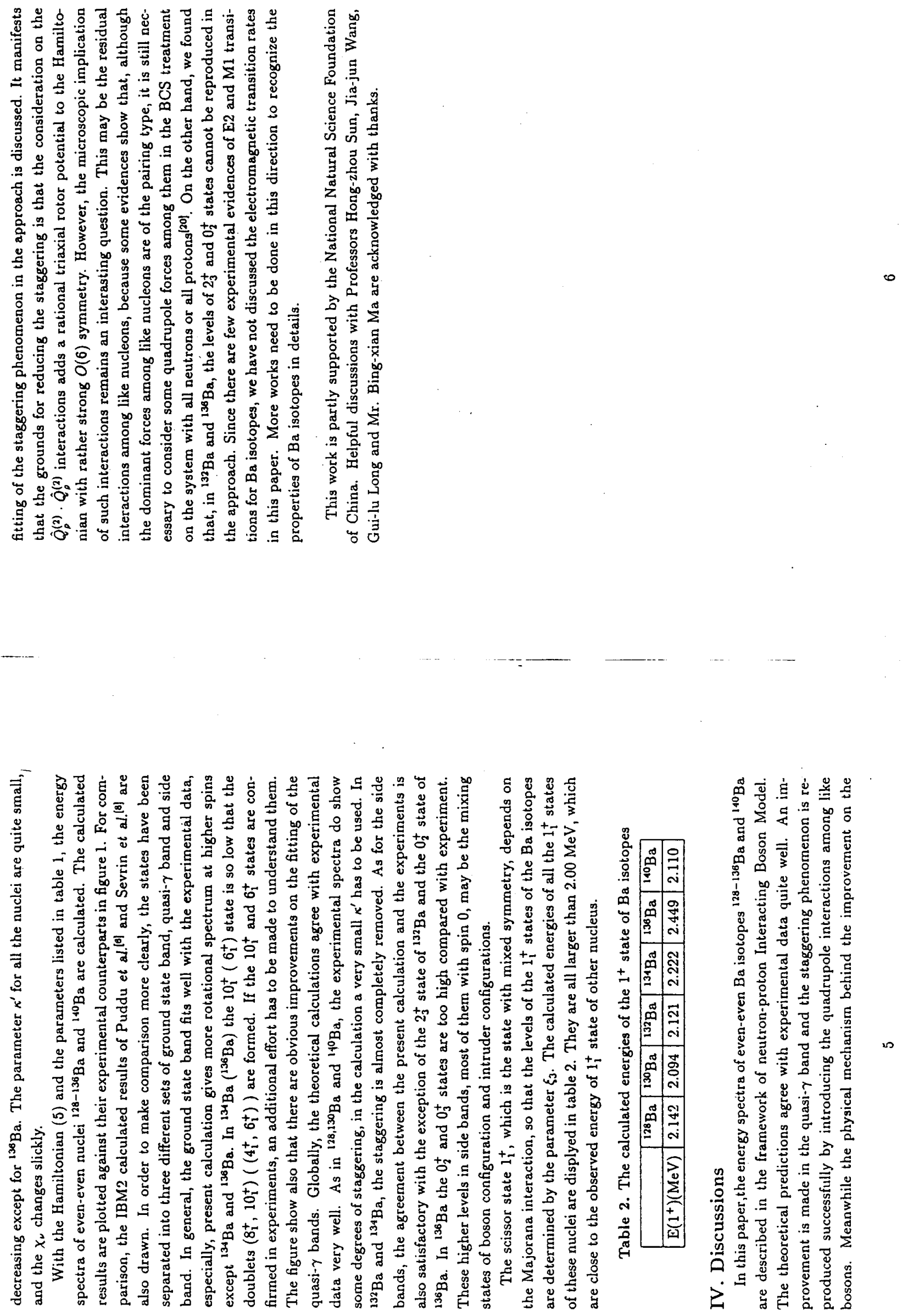


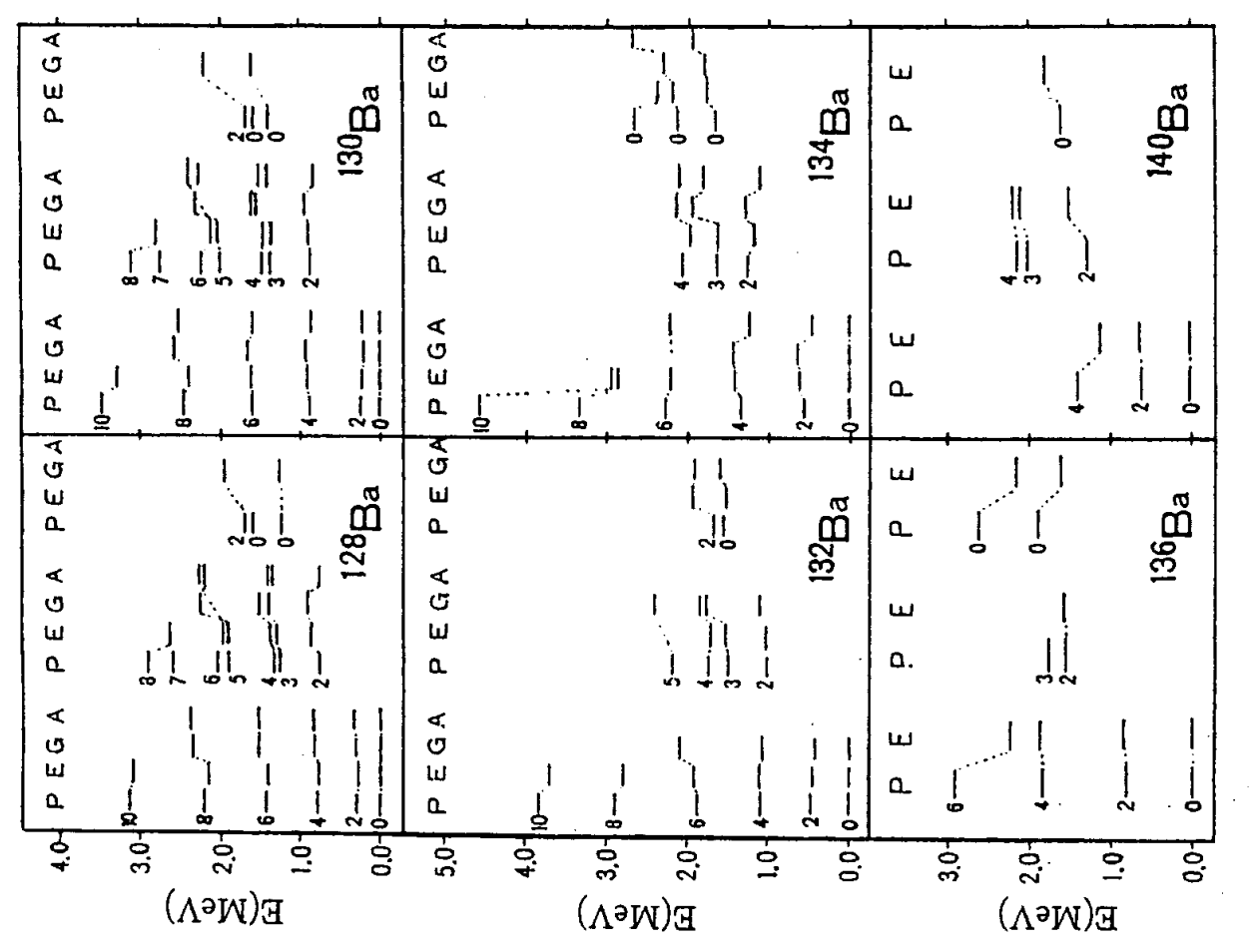

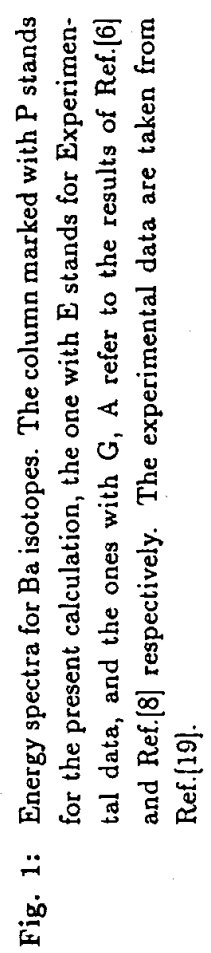

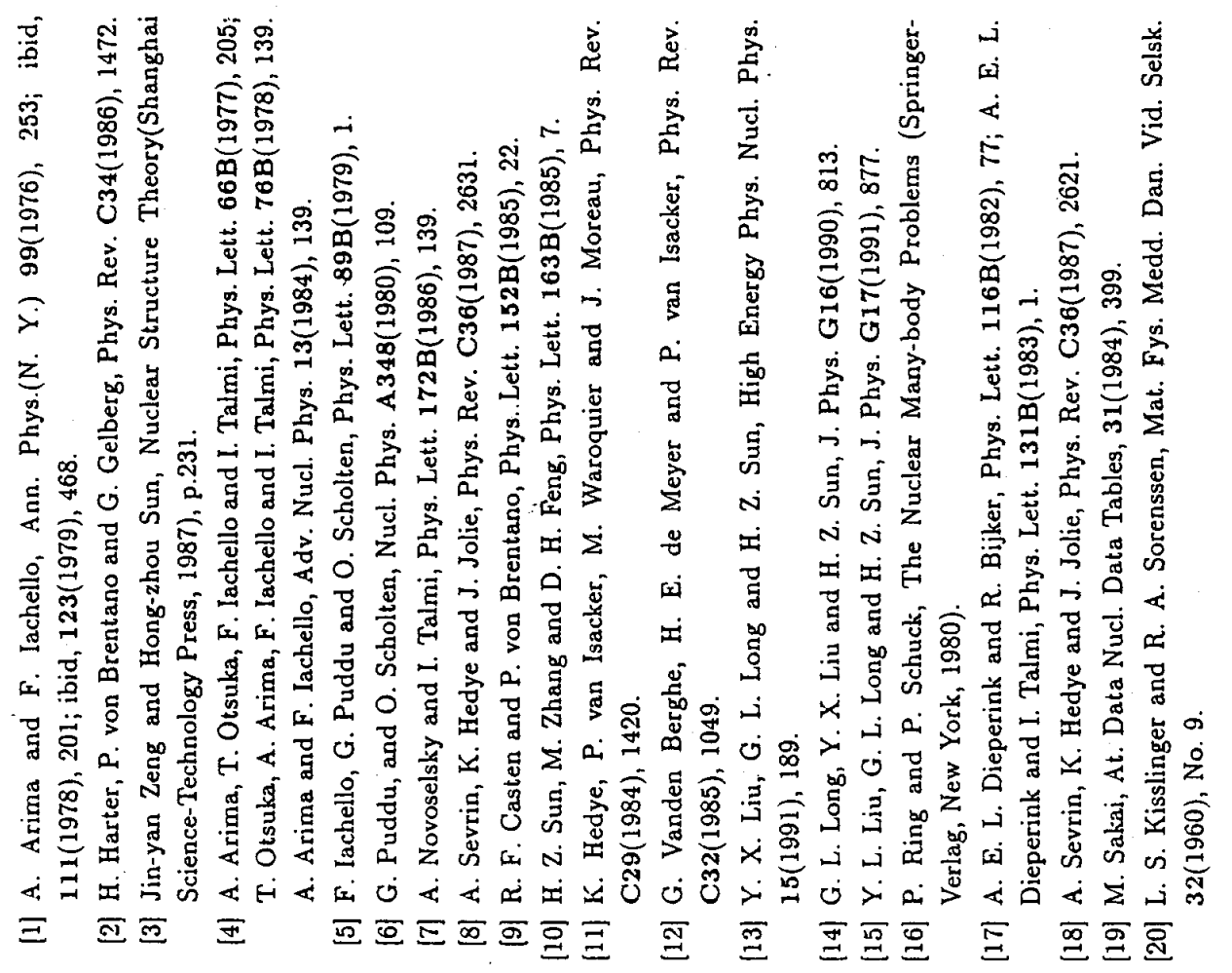

